\title{
Socio-economic status over the life-course and depressive symptoms in men and women in Eastern Europe.
}

\author{
Amanda Nicholson (1) \\ Hynek Pikhart (1) \\ Andrzej Pajak (2) \\ Sofia Malyutina (3) \\ Ruzena Kubinova (4) \\ Anne Peasey (1) \\ Roman Topor-Madry (2) \\ Yuri Nikitin (3) \\ Nada Capkova (4) \\ Michael Marmot (1) \\ Martin Bobak (1)
}

1 International Institute for Health and Society, Department of Epidemiology and Public Health, University College London, UK

2 Department of Epidemiology and Population Studies, Jagiellonian University, Krakow, Poland

3 Institute of Internal Medicine, Russian Academy of Medical Sciences, Novosibirsk, Russia

4 Centre for Environmental Health, National Institute of Public Health, Prague, Czech Republic

Correspondence: Dr Amanda Nicholson, Department of Epidemiology and Public Health, University College London, 1-19 Torrington Place, London WC1E 6BT, UK. Tel +442076791725 Fax : +44 2078130280

email: amanda.nicholson@ucl.ac.uk

Word count (text): 3747

Word count (abstract): 242

Tables: 5 


\begin{abstract}
Objective: Research into social inequalities in depression has studied western populations but data from non-western countries are sparse. In this paper, we investigate the extent of social inequalities in depression in Eastern Europe, the relative importance of social position at different points of the life-course, and whether social patterning of depression differs between men and women.
\end{abstract}

Method: A cross-sectional study examined 12,053 men and 13,582 women in Russia, Poland and the Czech Republic. Depressive symptoms (16 or above on the CESD-20) were examined in relation to socio-economic circumstances at three phases of the lifecourse: childhood (household amenities and father's education); own education; current circumstances (financial difficulties and possession of household items)

Results: Pronounced social differences in depression exist in men and women throughout Eastern Europe. Depression was largely influenced by current circumstances rather than by early life or education, with effects stronger in Poland and Russia. Odds ratios in men

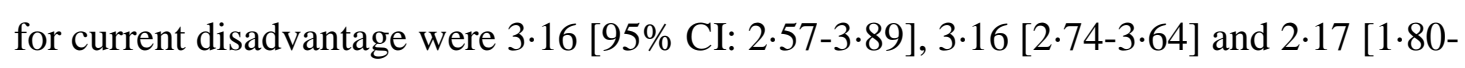
2.63] in Russia, Poland and the Czech Republic respectively. Social variables did not explain the female excess in depression, which varied from 2.91 [2.58-3.27] in Russia to 1.90 [1.74-2.08] in Poland. Men were more affected by adult disadvantage than women, leading to narrower sex differentials in the presence of disadvantage.

Limitations: Cross-sectional data with recall of childhood conditions were used.

Conclusion: Current social circumstances are the strongest influence on increased depressive symptoms in countries which have recently experienced social changes. 242 words. Key words: depressive symptoms; life-course epidemiology; Eastern Europe; social deprivation. 


\section{Introduction}

Depression is one of the leading causes of ill-health and disability throughout the world.(Murray et al. 1997) Despite good evidence of exogenous factors and stress contributing to the aetiology of depression,(Gelder et al. 1985) the relationship of depression to social position and disadvantage has been less clear cut than for other psychiatric disorders. A recent meta-analysis confirmed that depression is more prevalent in more deprived social groups(Lorant et al. 2003) but the nature and underlying causes of social inequality in depression remain unclear.

Most of the existing studies on social position and depression report on populations in America or western Europe. Given the background of great social upheaval, widespread hardship and increasing mortality in Eastern Europe,(Marmot et al. 2005) the role of depression as a mediator between social factors and physical ill-health(Gallo et al. 1999) is potentially important. In addition, examining the relationship between social variables and depression in societies which have been organized in a fundamentally different way to those in the West may provide new insights into our understanding of the social determinants of depression.

Research on the epidemiology and aetiology of depression has long realised the potential importance of the life-course. For example, Brown and Harris described the effects of adverse childhood emotional experiences on adult mental health.(Brown et al. 1978) However, the importance of social position at different points of the life-course for adult 
depression has been less extensively studied. It is plausible that privilege in early life and high education protect against adult adversity leading to depression. Existing work in the West has found some evidence of an enduring effect of both childhood social disadvantage and low education on adult depression independent of adult circumstances (Gilman et al. 2002; Kessler et al. 1997; Lundberg 1993; Power et al. 1997) but the impact on health of adverse social circumstances during the life course may differ in Eastern Europe.

Women have been found to have higher rates of depression than men in all countries studied.(Kuehner 2003; Weissman et al. 1984; Weissman et al. 1996) The reasons for this sex differential are not fully understood but social rather than biological factors are thought to predominate.(Kuehner 2003) Research in the US has suggested that women benefited more from education than men and that the sex differential narrowed in the most privileged groups.(Gilman et al 2002; Ross et al. 2006) This needs to be examined in different populations with different social structures.

In this report, we used a large population-based study in Russia, Poland and the Czech Republic to address three related questions: first, whether social inequalities in depression exist in Eastern Europe; second, what is the relative importance of social position at different points of the life- course; and third, whether the social pattern of depression in Eastern Europe differs between men and women. 


\section{Methods}

Study populations and subjects

The HAPIEE (Health, Alcohol and Psychosocial factors In Eastern Europe) study consists of three cohorts in Russia (Novosibirsk), Poland (Krakow) and six centres in the Czech Republic (Havirov/Karvina, Hradec Kralove, Jihlava, Kromeriz, Liberec and Usti nad Labem). Full details of the study methodology have been published elsewhere.(Peasey et al. 2006) Briefly, the cohorts consist of random samples of men and women aged 45-69 years old at baseline, stratified by gender and age, and selected from population registers. A total of 28,947 individuals completed the questionnaire with an overall response rate of 59\%. However subsequent investigation of subsamples of nonrespondents has indicated that a sizeable proportion on non-respondents had moved away or died before the start of the study, so that the true response rate is likely to be 5-10\% higher. An error in the interviewer protocol in Novosibirsk led to 2452 interviews being excluded; this report is thus based on 12,053 men and 13,582 women with valid data. The study received ethical approval from the UCL/UCLH joint research ethics committee and from ethical committees in each participating country. All participants gave informed consent.

\section{Measurements}

Depressive symptoms were assessed using the Center for Epidemiological StudiesDepression (CESD) scale.(Radloff 1977) This instrument comprises 20 questions on how frequently in the past week the participant has experienced a range of psychological and some physical symptoms. Responses (range 0-3) were summed up, and subjects with a 
score of 16 and above (shown to be predictive of major depressive disorder in a range of populations(Beekman et al. 1997; Lyness et al. 1997; Roberts et al. 1983)) have been classified as having depressive symptoms, here called depression.

Childhood disadvantage was assessed by access to household amenities when the participant was 10 years old (cold water tap, hot water tap, radio, fridge, kitchen, toilet). The items were summed and divided into approximate tertiles within countries. Adult height was used as a marker of childhood nutrition. Less than primary or no formal education of the participant's father was used as a marker of disadvantage (not available in the Czech Republic).

Participant's own education was classified into 4 point scale (primary or less, vocational, secondary or university) and analysed as both categorical and linear variables; education was also used as a dichotomous (primary/vocational versus secondary/university) variable.

Adult disadvantage was assessed by two dimensions. First, participants were asked in three separate questions if it ever happened that they did not have enough money for food, for clothes or ever had problems paying the bills. Each question had five response levels: all the time, often, sometimes, rarely or never. Participants who answered "often" or "all the time" to any one of these questions were classed as having financial difficulties. Second, subjects reported ownership of household items (microwave, dishwasher, washing machine, colour TV, car, freezer, cottage, satellite TV, video 
recorder, camcorder, mobile phone, telephone). The items owned were summed and divided into tertiles within countries. A summary measure of adult disadvantage was positive if a participant was either in the bottom tertile of household items or reported financial problems; and a cumulative score (0-2) was created according to how many markers of disadvantage were present.

Based on these analyses one socio-economic indicator for each stage of the life-course (childhood education, adult) was selected and combined to describe life trajectories, with upper case denoting disadvantage in that period e.g. CEA indicates disadvantage in all three periods. Similar methodology, creating a trajectory of exposure, has been used previously (Hallqvist et al. 2004; Naess et al. 2006; Nicholson et al. 2005).

\section{Statistical analyses}

Cross-tabulation and logistic models were done within sex and country groups using Stata version 8.2 (StataCorp LP, Texas, USA). Logistic regression models were ageadjusted using age divided into 5 year age-groups as a categorical variable. Interactions (between socioeconomic measures and country or sex) were tested by including crossproduct terms in either country- or sex-specific models, with significance assessed using likelihood-ratio tests.

\section{Results}

The prevalence of depression was higher in women than men in all countries (Tables 1 and 2). Men in Poland had the highest prevalence of depression (20.4\%) with prevalence 
in Russian and Czech men similar (15.0\% and 14.1\% respectively); the median CESD scores were 9,9 and 8, respectively (not shown in table). Russian and Polish women both reported high levels of depression (33.7\% and 32.9\% respectively) with prevalence lower in Czech women 24.1\%; median scores were 12, 11 and 10, respectively (not shown in table). Associations with age were weak (not shown in table). The sex differential was highest in Russia, 2.91 [2.58-3.27] compared to 1.95 [1.74-2.18] and 1.90 [1.74-2.08] in the Czech Republic and Poland respectively (interaction term for country, $\mathrm{p}<0 \cdot 01)$. Depressive symptoms were lowest in married men and women in all countries. The increase in risk of depression for single /divorced/ widowed women was less than that in men in Russia and Poland, $\mathrm{p}<0 \cdot 01$ for interaction terms for sex. The increase in depressive symptoms associated with divorce was greater in Poland than in the other two countries; odds ratios compared to married men and women were $2 \cdot 50$ [1.93-3.22] and $2.01[1.66-2.44]$ (interaction terms for country, $p=0.09$ and $p<0.01$ in men and women respectively, results not tabulated).

\section{Childhood disadvantage}

Men in the Czech Republic and Poland with fewer amenities were more likely to report high depressive symptoms, but in Russian men the association was not significant (Table 1). In women (Table 2), the associations were present in all countries but stronger in the Czech Republic (interaction term for country, $p=0 \cdot 05$ ). Father's education below primary was associated with approximately a 50\% increase in depression in men and women in Poland and Russia. Height was not associated with depressive symptoms in any country. 
There were no consistent sex differences in the effect of childhood disadvantage on adult depression.

\section{Own Education}

Educational gradients in depression were present in all countries and in both sexes. Gradients were stronger in Poland and the Czech Republic than in Russia but the interaction term for country was marginally significant for women only $(\mathrm{p}=0 \cdot 06)$. There was little evidence for a differential impact of education on depression between sexes, with only the effect of secondary education in Russia being stronger in women (interaction term for sex, $\mathrm{p}=0 \cdot 03$ ).

\section{Adult disadvantage}

The overall levels of difficulties were higher in Russia, and women were more likely than men to report financial difficulties in all countries. Both financial difficulties and possession of household items were strongly associated with depression in all countries so that the summary measure of any adult economic disadvantage was associated with a two to three times increased risk of depressive symptoms. The effects of any adult disadvantage were stronger in men than in women in Russia (interaction term for sex $\mathrm{p}<0.01)$ and in Poland $(\mathrm{p}=0.02)$. The effects of adult disadvantage were stronger in Poland and Russia than in the Czech Republic in both sexes (interaction term for country, $\mathrm{p}<0.01$ for men and $\mathrm{p}=0.02$ for women). The age-adjusted odds ratios of depression for both markers of adult disadvantage in the cumulative score versus none were $5 \cdot 50[4 \cdot 15$ 7.29], 5.03 [3·89-6.49] and 5.47 [3.90-7.70] in Russian, Polish and Czech men 
respectively and $3 \cdot 21[2 \cdot 67-3 \cdot 86], 4 \cdot 35[3 \cdot 58-5 \cdot 29]$ and $3 \cdot 33$ [2.62-4·26] in Russian, Polish and Czech women.

\section{Comparing childhood, education and adulthood}

Table 3 shows the effect of one selected measure from each period of the life-course (bottom tertile childhood amenities, own education dichotomized as primary/ vocational versus secondary /university; and any marker of adult disadvantage). Current adult economic disadvantage was the associated most strongly with depression in all groups and its effect was reduced only marginally by adjusting for social disadvantage at other periods of the life-course and for marital status. The effect of adult disadvantage remained weaker in the Czech Republic for both sexes in the adjusted models (interaction terms for country $\mathrm{p}>0.01$ for men and $\mathrm{p}=0.02$ for women). Additional adjustment for alcohol consumption, including binge drinking, reduced the effects of adult disadvantage only marginally (not shown).

The effect of childhood disadvantage on adult depression was weakened further by adjustment for other social variables and was significant only in Polish men and in the Czech Republic (interaction terms for country $p>0 \cdot 1$ for men and $p=0 \cdot 05$ for women). In the multivariate model, education was not associated with depression in men and only weakly so in Czech and Polish women.

\section{Life-course trajectory}


Considerable tracking of social status across the life-course was seen in all countries (Tables 4 and 5). For example, only $27 \%$ of Russian men who reported neither childhood disadvantage nor low education reported adult disadvantage compared to $52 \%$ of those with both childhood disadvantage and low education. In the Czech Republic the corresponding proportions for men were $16 \%$ and $42 \%$. The presence of adult disadvantage was the most important predictor of depressive symptoms in men with the contribution of education and childhood weak. There was more evidence of accumulation of disadvantage in Polish men, with the most disadvantaged group (CEA) having an odd ratios for depressive symptoms of $4 \cdot 11$ compared to the group with no disadvantage (cea), whereas the odds ratio was 3.23 for men with only adult disadvantage (ceA).

Women reported more depression than men at every level of the trajectory variable in every country. The sex differential narrowed in Russia and Poland with the presence of adult disadvantage, due to the greater increase in depressive symptoms in men. In Russia the sex differential was $3 \cdot 27$ [2.44-4.37] in the group with no disadvantage (cea), $2 \cdot 35$ [1.67-3.33] in the most deprived group (CEA) and 1.77 [1.31-2.38] in the group with only adult difficulties (ceA) (interaction term $\mathrm{p}=0 \cdot 07$ ).

\section{Discussion}

As far as we are aware this is the first study to examine the contribution of social position at different points of the life-course to depressive symptoms in adult life in Eastern Europe. In this large population-based study, we found strong social inequalities in depression in men and women throughout Eastern Europe, with men in the most 
disadvantaged groups up to five times more likely to report high depressive symptoms. Social differences in depression in Eastern Europe were more strongly associated with current economic circumstances than with early life conditions or education. Social variables did not explain the sex differences in depression but the sex differential was narrowed by the presence of adult disadvantage. We found little evidence for an enduring protective effect of education in either sex, or that women gained more from education than men.

\section{Limitations of the study}

There are certain limits to this international study. First, although the CESD is one of the most internationally recognized and extensively validated instruments,(Fountoulakis et al. 2001) it is not a measure of clinical depression. Participants who score above the threshold of 16 points include people with minor distress states and anxiety disorders and the scale may also detect some stable facets of personality such as high negative affectivity.(Watson et al. 1984) However Lorant found that the social gradient was greater for clinical depression measures than for depressive symptoms suggesting that we are not overestimating social differences.(Lorant et al 2003) Elevated depressive symptoms are an important public health issue in their own right as they have been shown to be associated with an increased risk of CHD.(Ferketich et al. 2000; Penninx et al. 1999)

Second, comparisons between countries may be affected by different translations and interpretation of the CESD. The CESD has been successfully used in many different 
countries, including Poland, Russia (Andriushchenko et al. 2003) and the Czech Republic (Osecka 1999). The translations used in this study has been validated in Poland (Dojka et al. 2003) but not formally in Russia or the Czech Republic and it is possible that the instrument may be operating differently in the various countries. However, given the good internal consistency of the CESD and similar associations of depressive symptoms in the three countries, this is unlikely. The mode of administration of the CESD differed between countries, with self-report in the Czech Republic and interviewer-administered in Poland and Russia. There is evidence that using an interviewer may lead to under-reporting(Chan et al. 2004) but we found lower levels of depressive symptoms in the Czech Republic. We used the same cut-point of 16 in all countries and to ensure that this was not creating artificial differences between countries, analyses were repeated using both the CESD score as a linear variable and with a higher cut-point of 20. The results were similar to those reported here, with the effect of adult disadvantage predominant, and stronger in Russia and Poland than in the Czech Republic.

Third, self-reported cross-sectional data are not ideal for an examination of the lifecourse. Recall of conditions in earlier periods of life may be inaccurate, leading to a dilution of associations, or can be affected by current mental state, leading to an overestimate of the association with depression. However other work, using a lifegrid method, has demonstrated accurate recall of similar material conditions in childhood fifty years later (Berney et al. 1997). Similarly, depressed participants may report their current situation more adversely. Such biased reporting may account for some of the association between financial difficulties and depression, but the other social variables, such as 
childhood amenities, father's education, own education and possession of household items, are factual recall rather than subjective assessment, and are therefore less prone to such bias. This may contribute to the stronger associations seen between depression and current conditions.

Finally, cross-sectional data have limited capacity to assess reverse causality, i.e. how much of the observed associations between social disadvantage and depression are due to depression affecting social functioning and thus reducing economic position. Clinical depression is a recurring disease which may affect life chances. Lorant(Lorant et al 2003) found that social differences were greatest for persistent depression. We do not have longitudinal data to look at persistence and it is possible that those who report adult adversity have suffered from depression throughout their lives and hence have been less able to cope with recent changes. Childhood conditions or father's education are unlikely to have been affected by the participant's own mental state, although a genetic tendency to depression might affect the associations. This is also consistent with our findings of weaker associations with earlier periods of life. The study design requires caution when inferring causality from the associations reported here.

\section{Differences between countries}

The prevalence of depressive symptoms was lowest in the Czech Republic in both sexes, similar to findings from our pilot study (on a different sample) in 2000,(Bobak et al. 2006) but differences between countries were not dramatic and the rates were in the range of those reported elsewhere e.g. in Spain (12\% and 39\% in men and women 
respectively),(Zunzunegui et al. 2001) Korea (35\% and $42 \%$ in men and women respectively)(Kim et al. 2005) and the UK (39\%).(Weich et al. 2002) Overall, depressive symptoms did not seem systematically associated with societal disruption.

In all countries there was clear evidence of tracking of social conditions across the lifecourse. This phenomenon is well recognised in western countries(Kuh et al. 1991; Kuh et al. 1997) but has been rarely documented in Eastern Europe.(Nicholson et al 2005) We found differences between the countries in the associations between social position at different stages of life and adult depression. The effect of childhood disadvantage was stronger in men and the effect of adult disadvantage was weaker in both sexes in the Czech Republic. No effect of social disadvantage from childhood was found in Russia or in Polish women. Education was included as a measure of early adult social status but as the associations in Tables 4 and 5 show, it is influenced by childhood (or adolescent) social conditions (working perhaps via influences on educational development and economic pressure to leave education) and in turn influences adult social conditions. The education effect on depression was modest in all countries, with the unadjusted effect largely due to tracking across to improved adult circumstances rather than an independent protective effect.

Previous work on social position during the life-course and adult depression in the US and western Europe found some evidence of an enduring independent effect of childhood social disadvantage on adult depression,(Gilman et al 2002; Kessler et al 1997; Lundberg 1993; Power et al 1997) and specifically education has been shown to be related to 
depression in western populations.(Gilman et al 2002; Lorant et al 2003; Miech et al. 2005; Ross et al 2006) For example, Gilman in the US reported a 70\% increased risk of major depression in participants whose fathers were in manual occupations during their childhood and a 70\% increased risk in participants with fewest years of education.(Gilman et al 2002) This is stronger than the 20-50\% increased risks seen in this study.

The weak or absent effects from earlier life-course periods seen in this study may reflect that our study population was older (Gilman et al 2002) but another explanation is that we used a different outcome from previous western studies (symptoms rather than depressive illness). The persistent effect of education is weaker in western studies which have examined a combined endpoint of common mental disorder (including depression and anxiety) (Kessler et al. 1994; Lewis et al. 1998). Data from developing countries are sparse but one study from Brazil found that education was more strongly associated with common mental disorder than income, suggesting a stronger effect of earlier life periods which we did not find.(Araya et al. 2003) It is also possible that, for example in Russia, childhood conditions were poor for so many people, that it loses its predictive strength. However, perhaps the most likely explanation is that the severity of current circumstances in Russia (and less so in Poland) is drowning out any persistent effects on mental health from childhood. The finding that adult disadvantage is more strongly associated with depression in Russia and Poland than in the more affluent Czech Republic is consistent with this explanation. 


\section{Differences between men and women}

The higher reporting of depressive symptoms in women is consistent with previous studies. In different countries, the female /male ratios in unipolar depression range between 1.5 and 3.0. The reasons underlying the female excess in depression are not clear but it has been suggested that it is more due to social roles than to genetic or hormonal effects.(Kuehner 2003) Russia has a high sex ratio of 2.9 with men reporting levels of depression similar to Czech men whereas Russian women report the highest prevalence, suggesting that Russian men may be reluctant to report distress symptoms.

Lorant's meta-analysis(Lorant et al 2003) found that the social gap in depression was wider in women but did not report whether this was seen with both income and education measures. Other studies have suggested that the impact of childhood social circumstances or education on adult depression might be greater in women(Gilman et al 2002; Ross et al 2006) and that the female excess was smaller in more privileged groups.(Ross et al 2006) We found little evidence that the effect of childhood or education was stronger in women: the only significant interaction term in the multivariate models between sex and childhood disadvantage was in Poland, where men were more affected than women. In addition, men were more affected by current circumstances than women in Russia and Poland. Hence the sex differential was smallest in the most disadvantaged groups, conflicting with findings in more affluent countries.

\section{Conclusions}


These results indicate that the determinants of depression may differ between stable affluent countries in the western world and countries where current conditions are more challenging. We found that current social circumstances were the primary influence on increased depressive symptoms in countries undergoing rapid societal change. This offers the prospect that improving current conditions might reduce the burden of distress, particularly in men. 


\section{References}

Andriushchenko AV, Drobizhev MI, Dobrovol'skii AV. 2003. [A comparative validation of the scale CES-D, BDI, and HADS(d) in diagnosis of depressive disorders in general practice]. Zh.Nevrol.Psikhiatr.Im S.S.Korsakova. 103, 11-18.

Araya R, Lewis G, Rojas G, Fritsch R. 2003. Education and income: which is more important for mental health? J Epidemiol Community Health. 57, 501-505.

Beekman ATF, Deeg DJH, van Limbeek J, Braam AW, de Vries MZ, Van Tilburg W. 1997. Criterion validity of the Center for Epidemiologic Studies Depression scale (CESD) : results from a community-based sample of older subjects in the Netherlands. Psychol Med. 27, 231-235.

Berney LR,Blane DB. 1997. Collecting retrospective data: accuracy of recall after 50 years judged against historical records. Soc.Sci.Med. 45, 1519-1525.

Bobak M, Pikhart H, Pajak A, Kubinova R, Malyutina S, Sebakova H, Topor-Madry R, Nikitin Y, Marmot M. 2006. Depressive symptoms in urban population samples in Russia, Poland and the Czech Republic. Br.J.Psychiatry. 188, 359-365.

Brown, G. W. \& Harris, T. 1978, Social origins of depression Tavistock Publications, London.

Chan KS, Orlando M, Ghosh-Dastidar B, Duan N, Sherbourne CD. 2004. The interview mode effect on the Center for Epidemiological Studies Depression (CES-D) scale: an item response theory analysis. Med.Care. 42, 281-289.

Dojka E, Gorkiewicz M, Pajak A. 2003. [Psychometric value of CES-D scale for the assessment of depression in Polish population]

Wartosc pomiarowa skali CES-D do oceny depresji w populacji polskiej. Psychiatr.Pol. 37, 281-292.

Ferketich AK, Schwartzbaum JA, Frid DJ, Moeschberger ML. 2000. Depression as an antecedent to heart disease among women and men in the NHANES I study. Arch Intern Med. 160, 1261-1268.

Fountoulakis K, Iacovides A, Kleanthous S, Samolis S, Kaprinis SG, Sitzoglou K, St Kaprinis G, Bech P. 2001. Reliability, validity and psychometric properties of the Greek translation of the Center for Epidemiological Studies-Depression (CES-D) Scale.

BMC.Psychiatry. 1, 3.

Gallo LC,Matthews KA. 1999. Do negative emotions mediate the association between scoioeconomic status and health? Ann NY Acad Sci. 896, 226-245.

Gelder, M., Gath, D., \& Mayou, R. 1985, Oxford Textbook of Psychiatry Oxford University Press, Oxford. 
Gilman SE, Kawachi I, Fitzmaurice GM, Buka SL. 2002. Socioeconomic status in childhood and the lifetime risk of major depression. Int.J.Epidemiol. 31, 359-367.

Hallqvist J, Lynch J, Bartley M, Lang T, Blane D. 2004. Can we disentangle life course processes of accumulation, critical period and social mobility? An analysis of disadvantaged socio-economic positions and myocardial infarction in the Stockholm Heart Epidemiology Program. Soc.Sci.Med. 58, 1555-1562.

Kessler RC, Davis CG, Kendler KS. 1997. Childhood adversity and adult psychiatric disorder in the US National Comorbidity Survey. Psychol.Med. 27, 1101-1119.

Kessler RC, McGonagle KA, Zhao S, Nelson CB, Hughes M, Eshleman S, Wittchen HU, Kendler KS. 1994. Lifetime and 12-month prevalence of DSM-1II-R psychiatric disorders in the United States. Arch Gen Psychiatry. 51, 8-19.

Kim E, Jo SA, Hwang JY, Shin C, Kim DK, Woo EK, Kim SS, Shin KR, Jo I. 2005. A survey of depressive symptoms among South Korean adults after the Korean financial crisis of late 1997: prevalence and correlates. Ann.Epidemiol. 15, 145-152.

Kuehner C. 2003. Gender differences in unipolar depression: an update of epidemiological findings and possible explanations. Acta psychiatr.scand. 108, 163-174.

Kuh D, Head J, Hardy R, Wadsworth M. 1997. The influence of education and family background on women's earnings in midlife: evidence from a British national cohort study. Br J Sociol Educ. 18, 385-405.

Kuh D,Wadsworth M. 1991. Childhood influences on adult male earnings in a longitudinal study. Br J Sociol. 42, 537-555.

Lewis G, Bebbington P, Brugha T, Farrell M, Gill B, Jenkins R, Meltzer H. 1998. Socioeconomic status, standard of living, and neurotic disorder. Lancet. 352, 605-609.

Lorant V, Deliege D, Eaton W, Robert A, Philipott P, Ansseau M. 2003. Socioeconomic inequalities in depression: A meta-analysis. American Journal of Epidemiology. 157, 98112.

Lundberg O. 1993. The impact of childhood living conditions on illness and mortality in adulthood. Soc.Sci.Med. 36, 1047-1052.

Lyness JM, Noel TK, Cox C, King DA, Conwell Y, Caine ED. 1997. Screening for depression in elderly primary care patients. Arch Intern Med. 157, 449-454.

Marmot M,Bobak M. 2005. Social and economic changes and health in Europe East and West. European Review. 13, 15-31.

Miech RA, Eaton WW, Brennan K. 2005. Mental health disparities across education and sex: a prospective analysis examining how they persist over the life course. J.Gerontol.B Psychol.Sci.Soc.Sci. 60 Spec No 2, 93-98. 
Murray CJL,Lopez AD. 1997. Alternative projections of mortality and disability by cause 1990-2020: global burden of disease study. Lancet. 349, 1498-1504.

Naess O, Hernes FH, Blane D. 2006. Life-course influences on mortality at older ages: Evidence from the Oslo Mortality Study. Social Science \& Medicine. 62, 329-336.

Nicholson A, Bobak M, Murphy M, Rose R, Marmot M. 2005. Socio-economic influences on self-rated health in Russian men and women--a life course approach. Soc.Sci.Med. 61, 2345-2354.

Osecka, L. 1999, Skala deprese CES-D - psychometricka analyza (Depression scale CESD: psychometric analysis) Czech Academy of Sciences, Brno.

Peasey A, Bobak M, Kubinova R, Malyutina S, Pajak A, Tamosiunas A, Pikhart H, Nicholson A, Marmot M. 2006. Determinants of cardiovascular disease and other noncommunicable diseases in Central and Eastern Europe: rationale and design of the HAPIEE study. BMC Public Health. 6, 255.

Penninx BWJH, Geerlings SW, Deeg DJH, van Eijk JTM, Van Tilburg W, Beekman TF. 1999. Minor and major depression and the risk of death in older persons. Archives of General Psychiatry. 56, 889-895.

Power C, Hertzman C, Matthews S, Manor O. 1997. Social differences in health: lifecycle effects between ages 23 and 33 in the 1958 British birth cohort. Am.J.Public Health. 87, 1499-1503.

Radloff LS. 1977. The CES-D scale: A self-report depression scale for research in the general population. Applied Psychological Measurement. 1, 385-401.

Roberts RE,Vernon SW. 1983. The Center for Epidemiologic Studies Depression scale: its use in a community sample. Am J Psychiatry. 140, 41-46.

Ross CE,Mirowsky J. 2006. Sex differences in the effect of education on depression: Resource multiplication or resource substitution? Soc.Sci.Med. 63, 1400-1413.

Watson D,Clark LA. 1984. Negative affectivity; the disposition to experience aversive emotional states. Psychological Bulletin. 96, 465-490.

Weich S, Blanchard M, Prince M, Burton E, Erens B, Sproston K. 2002. Mental health and the built environment: cross-sectional survey of individual and contextual risk factors for depression. Br.J.Psychiatry. 180, 428-433.

Weissman MM, Bland RC, Canino GJ, Faravelli C, Greenwald S, Hwu HG, Joyce PR, Karam EG, Lee CK, Lellouch J, Lepine JP, Newman SC, Rubio-Stipec M, Wells JE, Wickramaratne PJ, Wittchen H, Yeh EK. 1996. Cross-national epidemiology of major depression and bipolar disorder. JAMA. 276, 293-299. 
Weissman MM, Leaf PJ, Holzer CE, III, Myers JK, Tischler GL. 1984. The epidemiology of depression. An update on sex differences in rates. J.Affect.Disord. 7, 179-188.

Zunzunegui MV, Beland F, Otero A. 2001. Support from children, living arrangements, self-rated health and depressive symptoms of older people in Spain. International journal of epidemiology. 30, 1090-1099. 
Table 1. Numbers of subjects, prevalence and odds ratio [95\% confidence interval] of depressive symptoms by childhood circumstances, own education and adult conditions in men, by country.

\begin{tabular}{|c|c|c|c|c|c|c|c|c|c|}
\hline & $\mathbf{N}$ & $\begin{array}{l}\text { R } \\
\text { Depr. } \\
16+ \\
(\%)\end{array}$ & $\begin{array}{l}\text { USSia } \\
\text { Odds Ratio } \\
\text { (age adjusted ) }\end{array}$ & $\mathbf{N}$ & $\begin{array}{l}\quad P \\
\text { Depr. } \\
16+ \\
(\%)\end{array}$ & $\begin{array}{l}\text { oland } \\
\text { Odds Ratio } \\
\text { (age adjusted ) }\end{array}$ & $\mathbf{N}$ & $\begin{array}{l}\text { Czech } \\
\text { Depr. } \\
16 \% \\
(\%)\end{array}$ & $\begin{array}{l}\text { Republic } \\
\text { Odds Ratio } \\
\text { (age adjusted ) }\end{array}$ \\
\hline Overall & 3104 & $15 \cdot 0$ & - & 5114 & $20 \cdot 4$ & - & 3835 & $14 \cdot 1$ & - \\
\hline Childhood disadvan & tage & & & & & & & & \\
\hline Amenities score tertile & & & & & & & & & \\
\hline Top & 586 & $12 \cdot 1$ & 1 & 1624 & $18 \cdot 0$ & 1 & 1520 & $13 \cdot 5$ & 1 \\
\hline Mid & 948 & $15 \cdot 6$ & $1.24[0.91-1.70]$ & 1334 & $18 \cdot 4$ & $1 \cdot 10[0 \cdot 91-1 \cdot 33]$ & 1066 & $12 \cdot 3$ & $1.03[0.86-1 \cdot 32]$ \\
\hline Bottom & 1550 & $15 \cdot 7$ & $1 \cdot 17[0.86-1 \cdot 59]$ & 2015 & $23 \cdot 1$ & $1 \cdot 53[1 \cdot 29-1 \cdot 83]$ & 1091 & $15 \cdot 2$ & $1 \cdot 36[1.06-1 \cdot 74]$ \\
\hline $\begin{array}{l}\text { Linear } \\
\text { (per } 1 \text { unit decrease) }\end{array}$ & & & $1.03[0.97-1.11]$ & & & $1 \cdot 11[1 \cdot 07-1 \cdot 16]$ & & & $1 \cdot 11[1 \cdot 03-1 \cdot 20]$ \\
\hline Father's education & & & & & & & & & \\
\hline Primary / above & 2490 & $13 \cdot 8$ & 1 & 4609 & $19 \cdot 8$ & 1 & & & \\
\hline Less than primary & 324 & $18 \cdot 5$ & $1 \cdot 37[1 \cdot 00-1 \cdot 86]$ & 454 & $26 \cdot 9$ & $1 \cdot 56[1 \cdot 25-1 \cdot 95]$ & N/A & & \\
\hline Height (per SD decrea & & & $0.96[0.87-1.07]$ & & & $1.06[0.98-1 \cdot 14]$ & & & $1 \cdot 01[0 \cdot 91-1 \cdot 12]$ \\
\hline Own education & & & & & & & & & \\
\hline University & 1051 & $14 \cdot 4$ & 1 & 1535 & $16 \cdot 4$ & 1 & 717 & $11 \cdot 4$ & 1 \\
\hline Secondary & 1189 & $14 \cdot 4$ & $1 \cdot 01[0 \cdot 80-1 \cdot 28]$ & 1680 & $20 \cdot 8$ & $1 \cdot 34[1 \cdot 12-1 \cdot 60]$ & 1216 & $13 \cdot 5$ & $1 \cdot 21[0.91-1 \cdot 61]$ \\
\hline Vocational & 682 & $15 \cdot 3$ & $1.07[0.81-1.40]$ & 1407 & $21 \cdot 6$ & $1.40[1 \cdot 16-1.69]$ & 1663 & $14 \cdot 6$ & $1 \cdot 32[1 \cdot 01-1 \cdot 72]$ \\
\hline Primary /less & 182 & $21 \cdot 4$ & $1.44[0.97-2 \cdot 16]$ & 488 & $28 \cdot 1$ & $2 \cdot 04[1.60-2 \cdot 60]$ & 220 & $21 \cdot 4$ & $2 \cdot 16[1 \cdot 45-3 \cdot 21]$ \\
\hline $\begin{array}{l}\text { Linear } \\
\text { (per } 1 \text { unit decrease) }\end{array}$ & & & $1.08[0 \cdot 97-1 \cdot 21]$ & & & $1 \cdot 22[1 \cdot 14-1 \cdot 31]$ & & & $1.20[1.08-1 \cdot 34]$ \\
\hline Adult disadvantage & & & & & & & & & \\
\hline Financial difficulties & & & & & & & & & \\
\hline No /sometimes & 2365 & $10 \cdot 4$ & 1 & 4321 & $17 \cdot 1$ & 1 & 3473 & $12 \cdot 2$ & 1 \\
\hline Always /often & 738 & $29 \cdot 5$ & $3 \cdot 51[2 \cdot 85-4 \cdot 33]$ & 782 & $39 \cdot 0$ & $3 \cdot 08[2 \cdot 61-3 \cdot 63]$ & 336 & $31 \cdot 6$ & $3 \cdot 30[2 \cdot 56-4 \cdot 24]$ \\
\hline Household items tertile & & & & & & & & & \\
\hline Top & 1344 & $11 \cdot 5$ & 1 & 1958 & $13 \cdot 9$ & 1 & 1055 & $9 \cdot 6$ & 1 \\
\hline Mid & 1073 & $12 \cdot 7$ & $1.09[0.85-1.40]$ & 2245 & $20 \cdot 1$ & $1.60[1.36-1.89]$ & 1689 & $12 \cdot 8$ & $1.45[1.13-1.87]$ \\
\hline Bottom & 677 & $25 \cdot 6$ & $2 \cdot 53[1.97-3 \cdot 25]$ & 849 & $36 \cdot 0$ & $3 \cdot 73[3 \cdot 07-4 \cdot 52]$ & 868 & $20 \cdot 9$ & $2 \cdot 69[2 \cdot 06-3 \cdot 52]$ \\
\hline $\begin{array}{l}\text { Linear } \\
\text { (per } 1 \text { unit decrease) }\end{array}$ & & & $1 \cdot 19[1 \cdot 13-1 \cdot 24]$ & & & $1 \cdot 25[1 \cdot 21-1 \cdot 30]$ & & & $1 \cdot 20[1 \cdot 15-1 \cdot 26]$ \\
\hline Any current disadvanto & & & & & & & & & \\
\hline No & 1997 & $9 \cdot 4$ & 1 & 3746 & $15 \cdot 0$ & 1 & 2778 & $11 \cdot 3$ & 1 \\
\hline Yes & 1106 & $25 \cdot 1$ & $3 \cdot 16[2 \cdot 57-3 \cdot 89]$ & 1361 & $35 \cdot 6$ & $3 \cdot 16[2 \cdot 74-3 \cdot 64]$ & 1048 & $21 \cdot 3$ & $2 \cdot 17[1 \cdot 80-2 \cdot 63]$ \\
\hline $\begin{array}{l}\text { Depressive s } \\
\text { Childhood a } \\
\text { Household it } \\
\text { video record }\end{array}$ & $\begin{array}{l}\text { ympton } \\
\text { menitie } \\
\text { ems: } m \\
\text { er, cam }\end{array}$ & $\mathrm{As}=\mathrm{sco}$ & $\begin{array}{l}\text { re of } 16 \text { or above on } \\
\text { water tap, hot water } \\
\text { e, dishwasher, wash } \\
\text { mobile phone, teleph }\end{array}$ & CESD- & 20 & $\begin{array}{l}\text { e, kitchen, toilet. } \\
\text { lour TV, car, freeze }\end{array}$ & cotta & satelli & ite TV, \\
\hline
\end{tabular}


Table 2 . Numbers of subjects, prevalence and odds ratio [95\% confidence interval] of depressive symptoms by childhood circumstances, own education and adult conditions in women, by country.

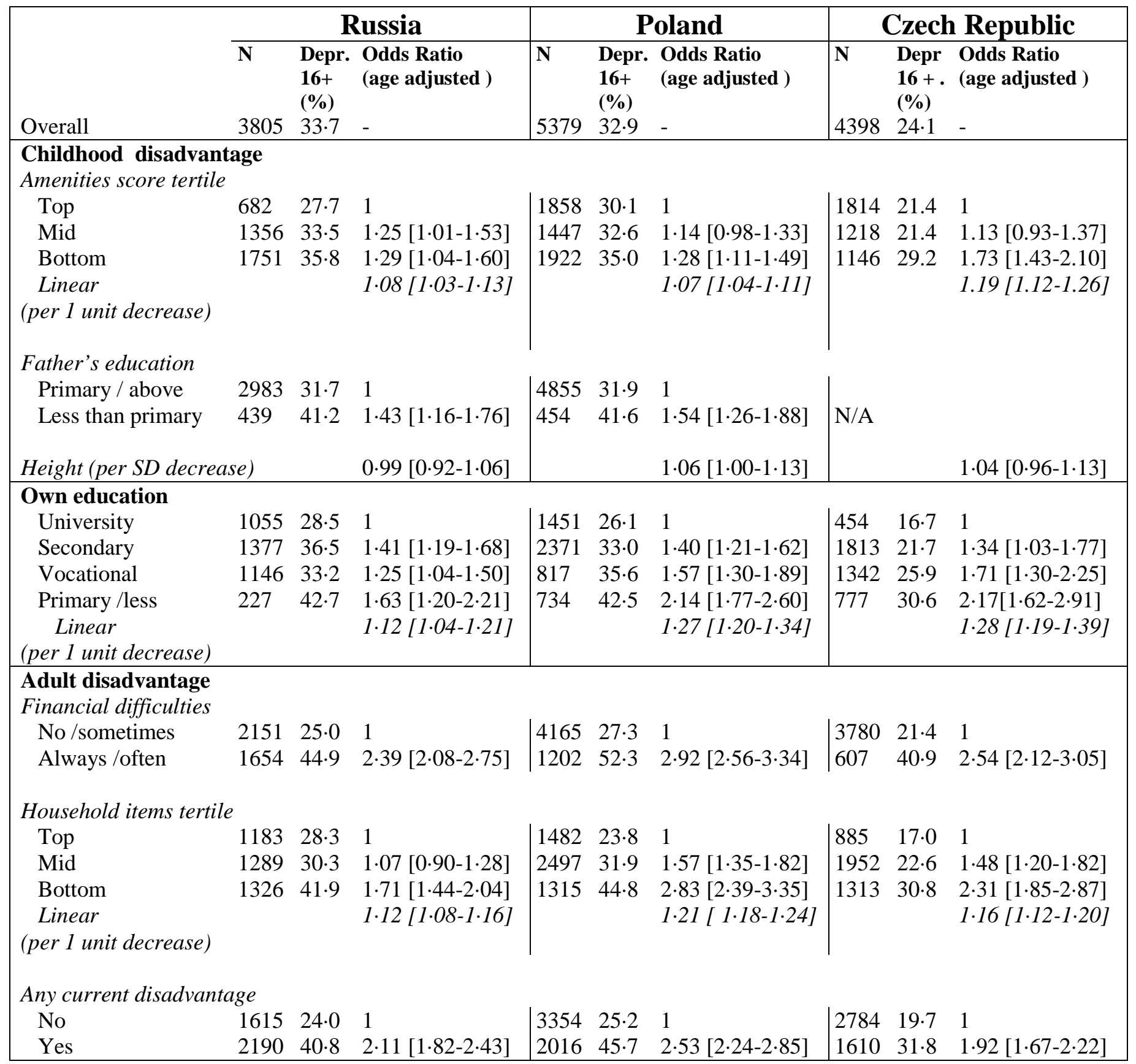

Depressive symptoms $=$ score of 16 or above on CESD-20

Childhood amenities : cold water tap, hot water tap, radio, fridge, kitchen, toilet.

Household items: microwave, dishwasher, washing machine, colour TV, car, freezer, cottage, satellite TV,

video recorder, camcorder, mobile phone, telephone.

Any adult disadvantage : bottom tertile household amenities or financial difficulties always/often 
Table 3: Odds ratio [95\% confidence interval] of depressive symptoms by social predictors from different phases of the lifecourse, by sex and country.

\begin{tabular}{|c|c|c|c|}
\hline Social predictors & $\begin{array}{l}\text { Individual models with } \\
\text { each social predictor } \\
\text { alone, adjusted for age }\end{array}$ & $\begin{array}{l}\text { Single model } \\
\text { including all } 3 \\
\text { social predictors, } \\
\text { adjusted for age } \\
\end{array}$ & $\begin{array}{l}\text { Single model including all } \\
3 \text { social predictors, } \\
\text { adjusted for age }+ \text { marital } \\
\text { status }\end{array}$ \\
\hline \multicolumn{4}{|c|}{ Men - Russia n=3084 } \\
\hline Bottom tertile childhood amenities & $1.00[0 \cdot 81-1 \cdot 24]$ & $0 \cdot 90[0.72-1 \cdot 12]$ & $0.89[0 \cdot 72-1 \cdot 11]$ \\
\hline Low education & $1.13[0.91-1.40]$ & $1.03[0 \cdot 83-1 \cdot 29]$ & $1 \cdot 04[0 \cdot 83-1 \cdot 31]$ \\
\hline Adult any disadvantage & $3 \cdot 14[2 \cdot 55-3 \cdot 86]$ & $3 \cdot 16[2 \cdot 56-3 \cdot 90]$ & $3 \cdot 04[2 \cdot 46-3 \cdot 76]$ \\
\hline \multicolumn{4}{|c|}{ Men - Poland $n=4955$} \\
\hline Bottom tertile childhood amenities & $1.47[1 \cdot 27-1 \cdot 70]$ & $1.36[1.17-1.60]$ & $1.39[1.18-1.63]$ \\
\hline Low education & $1.30[1.13-1.50]$ & $0.93[0.80-1.09]$ & $0.94[0 \cdot 80-1 \cdot 10]$ \\
\hline Adult any disadvantage & $3 \cdot 11[2 \cdot 68-3 \cdot 60]$ & $3 \cdot 08[2 \cdot 65-3 \cdot 58]$ & $2 \cdot 86[2 \cdot 44-3 \cdot 37]$ \\
\hline \multicolumn{4}{|c|}{ Men- Czech Republic n=3650 } \\
\hline Bottom tertile childhood amenities & $1 \cdot 36[1 \cdot 09-1 \cdot 69]$ & $1 \cdot 28[1 \cdot 03-1 \cdot 60]$ & $1.29[1.03-1.61]$ \\
\hline Low education & $1.23[1.02-1.49]$ & $1.03[0 \cdot 85-1 \cdot 26]$ & $1 \cdot 04[0 \cdot 85-1 \cdot 26]$ \\
\hline Adult any disadvantage & $2 \cdot 12[1 \cdot 73-2 \cdot 58]$ & $2 \cdot 06[1 \cdot 68-2 \cdot 53]$ & $1.94[1.57-2 \cdot 40]$ \\
\hline \multicolumn{4}{|c|}{ Women - Russia n=3789 } \\
\hline Bottom tertile childhood amenities & $1 \cdot 09[0 \cdot 94-1 \cdot 27]$ & $1.02[0 \cdot 88-1 \cdot 19]$ & $1.02[0 \cdot 88-1 \cdot 19]$ \\
\hline Low education & $1.06[0.92-1.22]$ & $1.03[0 \cdot 89-1.18]$ & $1.03[0 \cdot 89-1.19]$ \\
\hline Adult any disadvantage & $2 \cdot 11[1 \cdot 82-2 \cdot 44]$ & $2 \cdot 10[1 \cdot 82-2 \cdot 43]$ & $2 \cdot 03[1 \cdot 75-2 \cdot 35]$ \\
\hline \multicolumn{4}{|c|}{ Women - Poland n=5207 } \\
\hline Bottom tertile childhood amenities & $1 \cdot 21[1 \cdot 06-1 \cdot 37]$ & $1 \cdot 04[0 \cdot 91-1 \cdot 19]$ & $1.05[0 \cdot 92-1 \cdot 20]$ \\
\hline Low education & $1.48[1.30-1.67]$ & $1.22[1.06-1.40]$ & $1.22[1.07-1.41]$ \\
\hline Adult any disadvantage & $2 \cdot 49[2 \cdot 21-2 \cdot 81]$ & $2 \cdot 39[2 \cdot 12-2 \cdot 71]$ & $2 \cdot 31[2 \cdot 03-2 \cdot 62]$ \\
\hline \multicolumn{4}{|c|}{ Women - Czech Republic n=4156 } \\
\hline Bottom tertile childhood amenities & $1.63[1 \cdot 38-1.92]$ & $1.47[1 \cdot 24-1 \cdot 75]$ & $1.46[1 \cdot 23-1.73]$ \\
\hline Low education & $1.46[1.26-1.68]$ & $1.23[1.05-1.43]$ & $1.24[1.06-1.44]$ \\
\hline Adult any disadvantage & $1.91[1 \cdot 65-2 \cdot 22]$ & $1.79[1.53-2.08]$ & $1.64[1.40-1.94]$ \\
\hline
\end{tabular}

Low education $=$ primary /vocational education

Adult disadvantage $=$ either financial difficulties or bottom tertile of household items 
Table 4. Social disadvantage over life-course : summary trajectory groups and prevalence and age-adjusted odds ratio [95\% confidence interval] of depressive symptoms in men, by country.

\begin{tabular}{|c|c|c|c|c|c|}
\hline $\begin{array}{c}\text { Childhood } \\
\text { disadvantage }\end{array}$ & $\begin{array}{c}\text { Low } \\
\text { education }\end{array}$ & $\begin{array}{c}\text { Adult } \\
\text { disadvantage }\end{array}$ & $\begin{array}{l}\text { Group } \\
@\end{array}$ & $\begin{array}{c}\text { Depressed } \\
(\%)\end{array}$ & $\begin{array}{l}\text { OR }[95 \% \mathrm{CI}] \\
\text { (age-adjusted) }\end{array}$ \\
\hline \multicolumn{6}{|c|}{ Russia } \\
\hline \multirow{4}{*}{$\begin{array}{c}\text { No } \\
(\mathrm{n}=1534,50 \%)\end{array}$} & \multirow{2}{*}{$\begin{array}{l}\text { No } \\
(\mathrm{n}=1161,76 \%)\end{array}$} & No $(\mathrm{n}=845,73 \%)$ & cea & $9 \cdot 4$ & 1 \\
\hline & & Yes $(n=316,27 \%)$ & ceA & $26 \cdot 3$ & $3 \cdot 38[2 \cdot 40-4 \cdot 77]$ \\
\hline & \multirow{2}{*}{$\begin{array}{l}\text { Yes } \\
(\mathrm{n}=373,24 \%)^{* * *}\end{array}$} & No $(n=255,68 \%)$ & cEa & $9 \cdot 4$ & $0.99[0 \cdot 61-1 \cdot 61]$ \\
\hline & & Yes $(n=118,32 \%)$ & cEA & $28 \cdot 0$ & $3 \cdot 66[2 \cdot 30-5 \cdot 84]$ \\
\hline \multirow{4}{*}{$\begin{array}{c}\text { Yes } \\
(\mathrm{n}=1550,50 \%)\end{array}$} & \multirow{2}{*}{$\begin{array}{l}\text { No } \\
(\mathrm{n}=1067,69 \%)\end{array}$} & No $(n=654,62 \%)$ & Cea & $9 \cdot 5$ & $0.98[0 \cdot 68-1 \cdot 40]$ \\
\hline & & Yes $(\mathrm{n}=413,38 \%)^{* * *}$ & CeA & $23 \cdot 5$ & $2 \cdot 84[2 \cdot 02-3.98]$ \\
\hline & \multirow{2}{*}{$\begin{array}{l}\text { Yes } \\
(\mathrm{n}=483,31 \%)\end{array}$} & No $(n=234,48 \%)$ & CEa & $9 \cdot 8$ & $1.01[0.62-1.67]$ \\
\hline & & Yes $(n=249,52 \%)$ & CEA & $24 \cdot 5$ & $2.93[1.98-4.34]$ \\
\hline \multicolumn{6}{|c|}{ Poland } \\
\hline \multirow{4}{*}{$\begin{array}{c}\text { No } \\
(\mathrm{n}=2955,60 \%)\end{array}$} & \multirow{2}{*}{$\begin{array}{l}\text { No } \\
(\mathrm{n}=2175,74 \%)\end{array}$} & No $(n=1793,82 \%)$ & cea & $14 \cdot 1$ & 1 \\
\hline & & Yes $(\mathrm{n}=382,18 \%)^{* * *}$ & ceA & $34 \cdot 8$ & $3 \cdot 23[2 \cdot 52-4 \cdot 15]$ \\
\hline & \multirow{2}{*}{$\begin{array}{l}\text { Yes } \\
(\mathrm{n}=780,26 \%)^{* * *}\end{array}$} & No $(n=484,62 \%)$ & cEa & $12 \cdot 2$ & $0 \cdot 83[0 \cdot 61-1 \cdot 12]$ \\
\hline & & Yes $(n=296,38 \%)$ & cEA & $31 \cdot 1$ & $2 \cdot 71[2 \cdot 05-3 \cdot 59]$ \\
\hline \multirow{4}{*}{$\begin{array}{c}\text { Yes } \\
(n=2014,40 \%)\end{array}$} & \multirow{2}{*}{$\begin{array}{l}\text { No } \\
(\mathrm{n}=959,48 \%)\end{array}$} & No $(n=750,78 \%)$ & Cea & $16 \cdot 7$ & $1 \cdot 33[1 \cdot 05-1 \cdot 69]$ \\
\hline & & Yes $(\mathrm{n}=209,22)^{* * *}$ & CeA & $34 \cdot 5$ & $3 \cdot 53[2 \cdot 56-4 \cdot 86]$ \\
\hline & \multirow{2}{*}{$\begin{array}{l}\text { Yes } \\
(\mathrm{n}=1055,52 \%)\end{array}$} & No $(n=625,59 \%)$ & CEa & $16 \cdot 7$ & $1 \cdot 29[1.00-1 \cdot 66]$ \\
\hline & & Yes $(n=430,41 \%)$ & CEA & $38 \cdot 1$ & $4 \cdot 11[3 \cdot 23-5 \cdot 24]$ \\
\hline \multicolumn{6}{|c|}{ Czech Republic } \\
\hline \multirow{4}{*}{$\begin{array}{c}\text { No } \\
(\mathrm{n}=2573,70 \%)\end{array}$} & \multirow{2}{*}{$\begin{array}{l}\text { No } \\
(\mathrm{n}=1421,55 \%)\end{array}$} & No $(n=1188,(84 \%)$ & cea & $9 \cdot 8$ & 1 \\
\hline & & Yes $(\mathrm{n}=233,16 \%)^{* * *}$ & ceA & $21 \cdot 9$ & $2 \cdot 72[1 \cdot 88-3 \cdot 92]$ \\
\hline & \multirow{2}{*}{$\begin{array}{l}\text { Yes } \\
(\mathrm{n}=1152,45 \%)^{* * *}\end{array}$} & No $(n=765,66 \%)$ & cEa & $11 \cdot 1$ & $1 \cdot 12[0 \cdot 83-1 \cdot 50]$ \\
\hline & & Yes $(n=387,33 \%)$ & cEA & $20 \cdot 9$ & $2 \cdot 46[1 \cdot 80-3 \cdot 36]$ \\
\hline \multirow{4}{*}{$\begin{array}{c}\text { Yes } \\
(\mathrm{n}=1087,30 \%)\end{array}$} & \multirow{2}{*}{$\begin{array}{l}\text { No } \\
(\mathrm{n}=456 \cdot 42 \%)\end{array}$} & No $(n=352,77 \%)$ & Cea & $13 \cdot 1$ & $1.57[1.08-2 \cdot 27]$ \\
\hline & & Yes $(\mathrm{n}=104,22 \%)^{* * *}$ & CeA & $19 \cdot 2$ & $2 \cdot 56[1 \cdot 50-4 \cdot 38]$ \\
\hline & \multirow{2}{*}{$\begin{array}{l}\text { Yes } \\
(\mathrm{n}=631,58 \%)\end{array}$} & No $(n=365,57 \%)$ & CEa & $13 \cdot 4$ & $1 \cdot 63[1 \cdot 13-2 \cdot 34]$ \\
\hline & & Yes $(n=266,42 \%)$ & CEA & $19 \cdot 2$ & $2 \cdot 51[1.73-3.63]$ \\
\hline
\end{tabular}

Childhood disadvantage $=$ bottom tertile of household amenities

Low education $=$ primary /vocational education

Adult disadvantage $=$ either financial difficulties or bottom tertile of household items

@ $\mathrm{c} / \mathrm{C}=$ childhood disadvantage; $\mathrm{e} / \mathrm{E}=$ low education; $\mathrm{a} / \mathrm{A}=$ adult disadvantage; small letters /

CAPITALS = unexposed/exposed.

Chi-square test of the association between presence of childhood disadvantage and low education or between low education and presence of adult disadvantage $* * * \mathrm{p}>0.01$ 
Table 5. Social disadvantage over life-course : summary trajectory groups and prevalence and age-adjusted odds ratio [95\% confidence interval] of depressive symptoms in women, by country.

\begin{tabular}{|c|c|c|c|c|c|}
\hline $\begin{array}{c}\text { Childhood } \\
\text { disadvantage }\end{array}$ & $\begin{array}{c}\text { Low } \\
\text { education }\end{array}$ & $\begin{array}{c}\text { Adult } \\
\text { disadvantage }\end{array}$ & $\begin{array}{l}\text { Group } \\
\text { @ }\end{array}$ & $\begin{array}{c}\text { Depressed } \\
(\%)\end{array}$ & $\begin{array}{l}\text { OR [95\% CI] } \\
\text { (age-adjusted) }\end{array}$ \\
\hline \multicolumn{6}{|c|}{ Russia } \\
\hline \multirow{4}{*}{$\begin{array}{c}\text { No } \\
(n=2038,54 \%)\end{array}$} & \multirow{2}{*}{$\begin{array}{l}\text { No } \\
(\mathrm{n}=1313,64 \%)\end{array}$} & No $(n=664,51 \%)$ & cea & $25 \cdot 3$ & 1 \\
\hline & & Yes $(n=649,49 \%)$ & ceA & $38 \cdot 1$ & $1 \cdot 80[1.42-2 \cdot 28]$ \\
\hline & \multirow{2}{*}{$\begin{array}{l}\text { Yes } \\
(\mathrm{n}=725,36 \%) \mathrm{NS}\end{array}$} & No $(n=350,48 \%)$ & cEa & $19 \cdot 7$ & $0.73[0.53-1 \cdot 00]$ \\
\hline & & Yes $(n=375,52 \%)$ & cEA & $42 \cdot 4$ & $2 \cdot 14[1 \cdot 63-2 \cdot 80]$ \\
\hline \multirow{4}{*}{$\begin{array}{c}\text { Yes } \\
(n=1751,46 \%)\end{array}$} & \multirow{2}{*}{$\begin{array}{l}\text { No } \\
(\mathrm{n}=1110,63 \%)\end{array}$} & No $(n=404,36 \%)$ & Cea & $24 \cdot 5$ & $0.92[0 \cdot 69-1 \cdot 23]$ \\
\hline & & Yes $(\mathrm{n}=706,64 \%)^{* * *}$ & CeA & $40 \cdot 4$ & $1.88[1.48-2 \cdot 39]$ \\
\hline & \multirow{2}{*}{$\begin{array}{l}\text { Yes } \\
(\mathrm{n}=641,37 \%)\end{array}$} & No $(n=190,30 \%)$ & CEa & $25 \cdot 3$ & $0.96[0 \cdot 66-1 \cdot 40]$ \\
\hline & & Yes $(n=451,70 \%)$ & CEA & $43 \cdot 2$ & $2 \cdot 07[1 \cdot 58-2 \cdot 71]$ \\
\hline \multicolumn{6}{|c|}{ Poland } \\
\hline \multirow{4}{*}{$\begin{array}{c}\text { No } \\
(\mathrm{n}=3299,63 \%)\end{array}$} & \multirow{2}{*}{$\begin{array}{l}\text { No } \\
(\mathrm{n}=2686,81 \%)\end{array}$} & No $(n=1897,71 \%)$ & cea & $24 \cdot 0$ & 1 \\
\hline & & Yes $(\mathrm{n}=789,29 \%) * * *$ & ceA & $43 \cdot 2$ & $2 \cdot 44[2 \cdot 04-2 \cdot 91]$ \\
\hline & \multirow{2}{*}{$\begin{array}{l}\text { Yes } \\
(\mathrm{n}=613,19 \%)^{* * *}\end{array}$} & No $(n=325,53 \%)$ & cEa & $26 \cdot 8$ & $1 \cdot 16[0 \cdot 88-1 \cdot 51]$ \\
\hline & & Yes $(n=288,47 \%)$ & cEA & $50 \cdot 0$ & $3 \cdot 18[2 \cdot 46-4 \cdot 10]$ \\
\hline $\begin{array}{c}\text { Yes } \\
(n=1918,37 \%)\end{array}$ & $\begin{array}{l}\text { No } \\
(\mathrm{n}=1025,53 \%) \\
\text { Yes } \\
(\mathrm{n}=893,47 \%)\end{array}$ & $\begin{array}{l}\text { No }(\mathrm{n}=658,64 \%) \\
\text { Yes }(\mathrm{n}=367,36 \%)^{* * *} \\
\text { No }(\mathrm{n}=375,42 \%) \\
\text { Yes }(\mathrm{n}=518,58 \%)\end{array}$ & $\begin{array}{l}\text { Cea } \\
\text { CeA } \\
\text { CEa } \\
\text { CEA }\end{array}$ & $\begin{array}{l}25 \cdot 4 \\
41 \cdot 4 \\
27 \cdot 7 \\
47 \cdot 9 \\
\end{array}$ & $\begin{array}{l}1 \cdot 11[0 \cdot 90-1 \cdot 37] \\
2 \cdot 33[1 \cdot 84-2 \cdot 96] \\
1 \cdot 26[0 \cdot 98-1 \cdot 62] \\
3 \cdot 04[2 \cdot 47-3 \cdot 75] \\
\end{array}$ \\
\hline \multicolumn{6}{|c|}{ Czech Republic } \\
\hline \multirow{4}{*}{$\begin{array}{c}\text { No } \\
(n=3023,73 \%)\end{array}$} & \multirow{2}{*}{$\begin{array}{l}\text { No } \\
(\mathrm{n}=1787,60 \%)\end{array}$} & No $(n=1347,75 \%)$ & cea & $17 \cdot 2$ & 1 \\
\hline & & Yes $(\mathrm{n}=440,25 \%) * * *$ & ceA & $28 \cdot 0$ & $1.93[1 \cdot 50-2 \cdot 49]$ \\
\hline & \multirow{2}{*}{$\begin{array}{l}\text { Yes } \\
(\mathrm{n}=1236,40 \%)^{* * *}\end{array}$} & No $(n=704,57 \%)$ & cEa & $19 \cdot 2$ & $1 \cdot 15[0 \cdot 91-1 \cdot 45]$ \\
\hline & & Yes $(n=532,43 \%)$ & cEA & $29 \cdot 7$ & $2 \cdot 14[1 \cdot 69-2 \cdot 70]$ \\
\hline \multirow{4}{*}{$\begin{array}{c}\text { Yes } \\
(n=1143,27 \%)\end{array}$} & \multirow{2}{*}{$\begin{array}{l}\text { No } \\
(\mathrm{n}=401,35 \%)\end{array}$} & No $(n=259,65 \%)$ & Cea & $18 \cdot 5$ & $1.22[0 \cdot 86-1 \cdot 73]$ \\
\hline & & Yes $(\mathrm{n}=142,35 \%)^{* * *}$ & $\mathrm{CeA}$ & $32 \cdot 4$ & $2 \cdot 62[1 \cdot 78-3 \cdot 86]$ \\
\hline & \multirow{2}{*}{$\begin{array}{l}\text { Yes } \\
(\mathrm{n}=742,65 \%)\end{array}$} & No $(n=341,46 \%)$ & CEa & $28 \cdot 7$ & $2 \cdot 20[1 \cdot 65-2 \cdot 91]$ \\
\hline & & Yes $(n=401,54 \%)$ & CEA & $35 \cdot 4$ & $3 \cdot 00[2 \cdot 30-3 \cdot 90]$ \\
\hline
\end{tabular}

Childhood disadvantage $=$ bottom tertile of household amenities

Low education $=$ primary $/$ vocational education

Adult disadvantage $=$ either financial difficulties or bottom tertile of household items

@ $\mathrm{c} / \mathrm{C}=$ childhood disadvantage; $\mathrm{e} / \mathrm{E}=$ low education; $\mathrm{a} / \mathrm{A}=$ adult disadvantage; small letters /

CAPITALS = unexposed/exposed.

Chi-square test of the association between presence of childhood disadvantage and low education or between low education and presence of adult disadvantage $* * * \mathrm{p}>0.01$ 